\title{
Identification of MicroRNAs Involved in Growth Arrest and Apoptosis in Hydrogen Peroxide-Treated Human Hepatocellular Carcinoma Cell Line HepG2
}

\author{
Yuan Luo, ${ }^{1,2}$ Xinyu Wen, ${ }^{3}$ Ling Wang, ${ }^{3}$ Jing Gao, ${ }^{3}$ Zi Wang, ${ }^{1}$ Chunyan Zhang, \\ Pengjun Zhang, ${ }^{1}$ Chengrong $\mathrm{Lu}^{2}{ }^{2}$ Lianning Duan, ${ }^{2}$ and Yaping Tian ${ }^{1,3}$ \\ ${ }^{1}$ Core Laboratory of Translational Medicine, State Key Laboratory of Kidney Disease, Chinese PLA General Hospital, \\ Beijing 100853, China \\ ${ }^{2}$ Aviation Medicine Research Laboratory, Air Force General Hospital, PLA, Beijing 100142, China \\ ${ }^{3}$ Department of Clinical Biochemistry, Chinese PLA General Hospital, Beijing 100853, China
}

Correspondence should be addressed to Lianning Duan; duan_ln@126.com and Yaping Tian; tianyp61@gmail.com

Received 18 March 2016; Revised 1 July 2016; Accepted 13 July 2016

Academic Editor: Kum Kum Khanna

Copyright (C) 2016 Yuan Luo et al. This is an open access article distributed under the Creative Commons Attribution License, which permits unrestricted use, distribution, and reproduction in any medium, provided the original work is properly cited.

\begin{abstract}
Although both oxidative stress and microRNAs (miRNAs) play vital roles in physiological and pathological processes, little is known about the interactions between them. In this study, we first described the regulation of $\mathrm{H}_{2} \mathrm{O}_{2}$ in cell viability, proliferation, cycle, and apoptosis of human hepatocellular carcinoma cell line HepG2. Then, miRNAs expression was profiled after $\mathrm{H}_{2} \mathrm{O}_{2}$ treatment. The results showed that high concentration of $\mathrm{H}_{2} \mathrm{O}_{2}(600 \mu \mathrm{M})$ could decrease cell viability, inhibit cell proliferation, induce cell cycle arrest, and finally promote cell apoptosis. Conversely, no significant effects could be found under treatment with low concentration $(30 \mu \mathrm{M})$. miRNAs array analysis identified 131 differentially expressed miRNAs (125 were upregulated and 6 were downregulated) and predicted 13504 putative target genes of the deregulated miRNAs. Gene ontology (GO) analysis revealed that the putative target genes were associated with $\mathrm{H}_{2} \mathrm{O}_{2}$-induced cell growth arrest and apoptosis. The subsequent bioinformatics analysis indicated that $\mathrm{H}_{2} \mathrm{O}_{2}$-response pathways, including MAPK signaling pathway, apoptosis, and pathways in cancer and cell cycle, were significantly affected. Overall, these results provided comprehensive information on the biological function of $\mathrm{H}_{2} \mathrm{O}_{2}$ treatment in HepG2 cells. The identification of miRNAs and their putative targets may offer new diagnostic and therapeutic strategies for liver cancer.
\end{abstract}

\section{Introduction}

Hepatocellular carcinoma (HCC) is the most common primary liver cancer and accounts for about $80 \%$ of all cases of this disease. Globally, HCC is the fifth most common cancer, but also the third cause of cancer-related mortality $[1,2]$. It is established that various factors are associated with the development of HCC, including hepatitis virus infection, alcoholic liver damage, ingestion of aflatoxin B1, nonalcoholic fatty liver disease, obesity, diabetes mellitus, and iron accumulation. Although the dominant role of these risk factors in different countries or regions might vary, the occurrence and development of HCC are a multistep process associated with years of chronic inflammation of liver [3-5]. Inflammatory cells, including neutrophils, macrophages, mast cells, and dendritic and natural killer cells, are recruited within inflammatory sites to release chemical mediators, such as cytokines, chemokines, and reactive oxygen species (ROS). The latter, in turn, might play a vital pathogenic role in the long-term progression, originating from chronic inflammation to hepatitis and ultimately leading to cancer [6-8].

ROS are chemically reactive molecules containing oxygen. The group includes hydrogen peroxide $\left(\mathrm{H}_{2} \mathrm{O}_{2}\right)$, superoxide anion $\left(\mathrm{O}_{2}{ }^{-}\right)$, hydroxyl radical $\left(\mathrm{OH}^{*}\right)$, singlet oxygen $\left({ }^{1} \mathrm{O}_{2}\right)$, ozone $\left(\mathrm{O}_{3}\right)$, and some other small molecules. In a biological context, ROS are mainly deprived from oxidative metabolism as natural byproducts and play important roles in cell signaling and homeostasis. However, in some pathological conditions or during environmental stress, ROS levels 
can increase dramatically and lead to the disruption of the prooxidant/antioxidant equilibrium. This is known as oxidative stress and it could lead to damaging of many intracellular molecules, including DNA, RNA, lipids, and proteins [9-11]. Specifically, ROS can promote many aspects of tumor development and progression either directly by activating proinflammatory transcriptional factors such as NF- $\kappa$ B and AP-1 or indirectly by inducing DNA damage and oncogene activation [12]. Meanwhile, some latest studies have cast new light on the complicated interplay network between inflammation, oxidative stress, cancer, and microRNAs (miRNAs) [13, 14]. The latter, which are a series of small noncoding RNAs (containing about 22 nucleotides), could modulate gene expression through canonical base pairing between the seed sequences of themselves and $3^{\prime}$ untranslated region ( $3^{\prime}$ UTR) of target mRNAs. In general, miRNAs downregulate gene expression by inhibiting the translation and/or reducing the stability of target mRNAs and therefore provide a novel level of posttranscriptional regulation $[15,16]$.

Although publications in the past decade have described the involvement of miRNAs in almost all kinds of physiological and pathological processes, little is known about the specific mechanisms of the interaction between oxidative stress and miRNAs. To the best of our knowledge, no previous researches have reported the miRNAs expression profile in $\mathrm{H}_{2} \mathrm{O}_{2}$ treated human hepatocellular carcinoma cell lines. Therefore, in this study, we examined the changes of the miRNAs expression profiles in HepG2 cells upon treatment with $\mathrm{H}_{2} \mathrm{O}_{2}$. The target genes of significantly changed miRNAs were predicted by in silico prediction algorithms. Combined with biological experiments, we present a more holistic view indicating that $\mathrm{H}_{2} \mathrm{O}_{2}$-sensitive miRNAs regulate cell proliferation inhibition, cycle arrest, and apoptosis promotion.

\section{Materials and Methods}

2.1. Cell Culture. HepG2 cells were obtained from China infrastructure of cell line resources. The cells were maintained as a monolayer culture in Dulbecco's modified Eagle's medium (DMEM; Gibco, Invitrogen Life Technologies, Carlsbad, CA, USA) supplemented with $10 \%$ fetal bovine serum (FBS; Gibco, Invitrogen Life Technologies, Carlsbad, CA, USA), $100 \mathrm{IU} / \mathrm{mL}$ penicillin, and $100 \mu \mathrm{g} / \mathrm{mL}$ streptomycin. HepG2 cells were cultured in a humidified incubator with $5 \% \mathrm{CO}_{2}$ at $37^{\circ} \mathrm{C}$.

2.2. Cell Viability Assay. Cell viability and proliferation were quantified by Cell Counting Kit-8 (CCK-8; Dojindo Molecular Technologies, Inc., Kumamoto, Japan) according to the manufacturer's protocol. To assess the cell viability, cells were seeded into 96-well plates at a concentration of $8 * 10^{3}$ HepG2 cells/well and each group was repeated in 5 wells. After the cells were treated with various concentrations of $\mathrm{H}_{2} \mathrm{O}_{2}$ for 24 hours (h), $10 \mu \mathrm{L}$ CCK-8 was added into each well. After mixing, the cells were incubated for an additional $2 \mathrm{~h}$, and then a microplate reader (RT-6000; Rayto, Rayto Life and Analytical Sciences Co., Ltd., Guangdong, China) was used to measure the absorbance at $450 \mathrm{~nm}$ (OD450) for each well. The cell viability rates were calculated according to the following formula: the cell viability ratio $(\%)=[(\mathrm{As}-\mathrm{Ab}) /(\mathrm{Ac}-\mathrm{Ab})] *$ $100 \%$, where As is the OD450 of $\mathrm{H}_{2} \mathrm{O}_{2}$ experiment group, $\mathrm{Ab}$ is the OD450 of blank control group, and Ac is the OD450 of non- $\mathrm{H}_{2} \mathrm{O}_{2}$ control group. The cell viability graph was drawn in which the viability ratios were plotted at the vertical axis and $\mathrm{H}_{2} \mathrm{O}_{2}$ concentration was plotted at the horizontal axis. The IC50 (half maximal inhibitory concentration) value, which represents the concentration of $\mathrm{H}_{2} \mathrm{O}_{2}$ in determining $50 \%$ of cell viability, was calculated by nonlinear regression analysis using GraphPad Prism software (San Diego, USA).

2.3. Cell Proliferation Assay. To assess the cell proliferation, cells were seeded into 96 -well plates at a concentration of $2 *$ $10^{3}$ HepG 2 cells/well and each group was repeated in 5 wells. After cells were treated with $0-100 \mu \mathrm{M}$ of $\mathrm{H}_{2} \mathrm{O}_{2}$ for $24 \mathrm{~h}$, the growth medium was replaced by fresh medium. At the following 4 detection time points (0, 24, 48, and $72 \mathrm{~h}), 10 \mu \mathrm{L}$ CCK-8 was added into each well. After mixing, cells were incubated for an additional $2 \mathrm{~h}$ before measuring the OD450. The cell proliferation graph was drawn, with OD450 plotted at the vertical axis and incubation time in hours at the horizontal axis.

2.4. Cell Cycle Assay. The cell cycle and apoptosis were analyzed by flow cytometry (FCM). To assess the cell cycle, HepG2 cells in logarithmic phase were harvested and plated in 24 -well culture plates at a concentration of $2 * 10^{5}$ cells $/ \mathrm{mL}$. Cells were starved overnight to achieve synchronization and then treated with $0-200 \mu \mathrm{M}$ of $\mathrm{H}_{2} \mathrm{O}_{2}$ for $24 \mathrm{~h}$. Using FCM instrument (FACS Calibur, BD Biosciences, San Jose, CA, USA), cell cycle was detected with cycle test Plus DNA reagent kit (BD Biosciences, San Jose, CA, USA) according to the manufacturer's instructions.

2.5. Cell Apoptosis Assay. To assess the level of apoptosis, HepG2 cells were plated in 24-well culture plates in the same concentration as mentioned above. After cell adhering, 0$800 \mu \mathrm{M}$ of $\mathrm{H}_{2} \mathrm{O}_{2}$ were added and cells were incubated for $24 \mathrm{~h}$. The Annexin V-PE/7-AAD Apoptosis Detection Kit (BD Biosciences, San Jose, CA, USA) was used to detect cell apoptosis according to the manufacturer's instructions.

2.6. Determination of Total ROS. Intracellular ROS levels were also determined by FCM. HepG 2 cells were plated in 12 -well culture plates at a concentration of $2 * 10^{5}$ HepG2 cells/well. After cell adhering, $0-600 \mu \mathrm{M}$ of $\mathrm{H}_{2} \mathrm{O}_{2}$ was added and cells were incubated for $24 \mathrm{~h}$. Cells were harvested and then incubated with $10 \mu \mathrm{M}$ 5-(and-6)-chloromethyl$2^{\prime}, 7^{\prime}$-dichlorodihydrofluorescein diacetate, acetyl ester (CMDCHF-DA, Invitrogen Life Technologies, Carlsbad, CA, USA), which could be cleaved by intracellular esterases and transformed into a fluorescent dye when oxidized at $37^{\circ} \mathrm{C}$ for $30 \mathrm{~min}$. The samples were analyzed by FCM instrument with CellQuest software. For each sample, 10,000 cells were analyzed.

2.7. RNA Preparation and miRNAs Microarray. HepG2 cells were seeded in $10 \mathrm{~cm}$ dishes and cultured as usual until they reached $80 \%$ confluence. The cells were treated with $\mathrm{H}_{2} \mathrm{O}_{2}$ 
$(0,30$, and $600 \mu \mathrm{M})$ for $24 \mathrm{~h}$ and each concentration was repeated in 3 dishes. Total RNA was extracted from the treated cells by using Trizol reagent (Invitrogen Life Technologies, Carlsbad, CA, USA) and then purified with a QIAGEN RNeasy Mini Kit (Qiagen, Valencia, CA, USA). After assessing the RNA's quality and quantity, the miRNAs microarray analysis (Affymetrix microRNA 4.0 Array, Santa Clara, CA, USA) was performed according to the manufacturer's instructions. Briefly, $1 \mu \mathrm{g}$ of total RNA was labeled with Biotin using the FlashTag ${ }^{\text {TM }}$ Biotin HSR RNA Labeling Kit (Genisphere, Hatfield, PA, USA) and then hybridized overnight with the array, which was washed, stained, and read by an GeneChip Scanner 3000 7G (Affymetrix).

2.8. Data Analysis of miRNAs Microarray. CEL-files of the raw data were first exported by Affymetrix GeneChip Command Console Software Version 4.0 (Affymetrix) and then uploaded to the website of Gminix-Cloud Biotechnology Information (GCBI, http://www.gcbi.com.cn/gclib/html/ index, Genminix Informatics Co., Ltd., Shanghai, China) for further analysis, including difference analysis of miRNAs profiles, prediction of miRNAs target genes, GO/pathway enrichment analysis, and miRNAs-gene-network and miRNAs-GO-network analysis. The miRNAs array data discussed in this paper has been uploaded to the NCBI Gene Expression Omnibus and is accessible through GEO series accession number GSE84406 (http://www.ncbi.nlm.nih.gov/ geo/query/acc.cgi?acc=GSE84406).

2.9. Statistical Analysis. Each experiment was performed independently at least 3 times with similar results. Student's $t$-test (two-tailed) was used to determine the statistical significance of quantitative data and Chi-square test was used for the statistical analysis of constituent ratio. $P<0.05$ was considered to be statistically significant.

\section{Results}

3.1. $\mathrm{H}_{2} \mathrm{O}_{2}$ Treatment Decreases Cell Viability and Inhibits Proliferation of HepG2 Cells. To determine the cytotoxicity of $\mathrm{H}_{2} \mathrm{O}_{2}$, we comprehensively detected the changes of viability, proliferation, cell cycle, and apoptosis in HepG2 cells. After exposure of HepG2 cells to $\mathrm{H}_{2} \mathrm{O}_{2}$ for $24 \mathrm{~h}, \mathrm{CCK}-8$ assay was firstly performed to determine the cell viability and proliferation. As shown in Figure 1, although $30 \mu \mathrm{M} \mathrm{H}_{2} \mathrm{O}_{2}$ seems to increase the cell viability and even proliferation, there were no statistically significant differences between them and control groups $(P>0.05)$. Conversely, in the presence of higher concentrations of $\mathrm{H}_{2} \mathrm{O}_{2}$, both cell viability and proliferation decreased significantly $(P<0.05)$. The IC50 value calculated through nonlinear regression analysis was $70.3 \mu \mathrm{M}$. These data suggest that $\mathrm{H}_{2} \mathrm{O}_{2}$ could cause an obvious dosedependent reduction of cell viability and proliferation, while no significant effect could be found at low concentrations of this compound.

3.2. $\mathrm{H}_{2} \mathrm{O}_{2}$ Treatment Induces Cell Cycle Arrest and Apoptosis of HepG2 Cells. FCM was utilized to detect the cell cycle and apoptosis of HepG2 cells after $\mathrm{H}_{2} \mathrm{O}_{2}$ treatment. As shown in

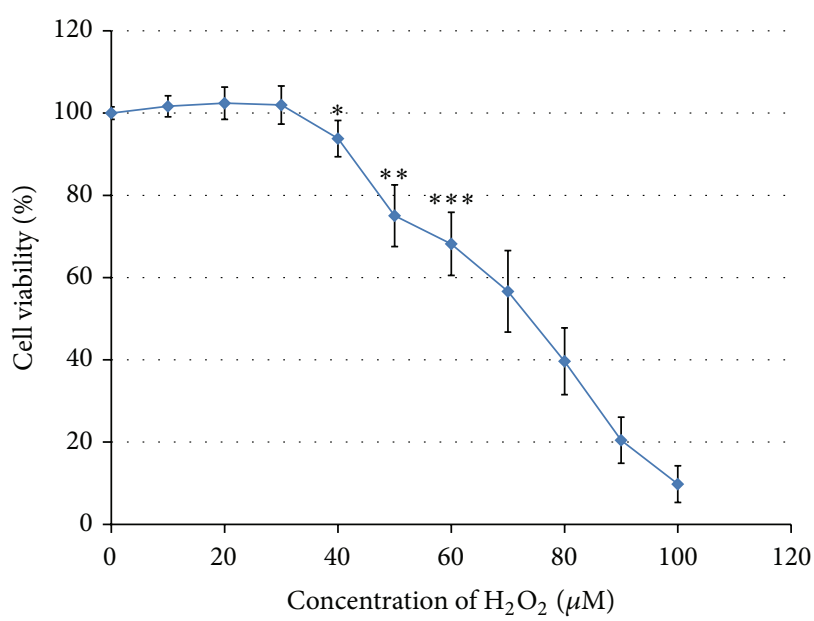

(a)

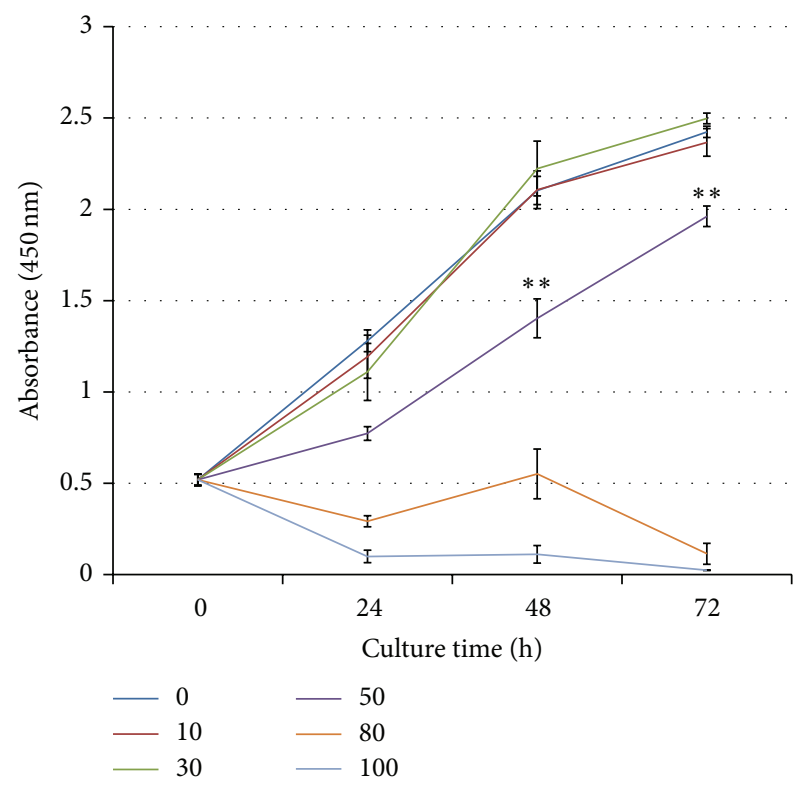

(b)

FIGURE 1: $\mathrm{H}_{2} \mathrm{O}_{2}$ treatment decreases cell viability and inhibits cell proliferation of HepG2 cells. (a) HepG2 cell viability was measured by CCK- 8 assay after $\mathrm{H}_{2} \mathrm{O}_{2}$ treatment for $24 \mathrm{~h}$. (b) After $\mathrm{H}_{2} \mathrm{O}_{2}$ treatment for $24 \mathrm{~h}$, the cell proliferation was quantified at different detection periods. Error bars denote mean $\pm \mathrm{SD}$. ${ }^{*} P<0.05 ;{ }^{* *} P<$ $0.01 ;{ }^{* * *} P<0.001$.

Figure 2, lower concentrations of $\mathrm{H}_{2} \mathrm{O}_{2}$ did not affect the cell cycle in HepG2 cells $(P>0.05)$. However, once the concentration of $\mathrm{H}_{2} \mathrm{O}_{2}$ was higher than $100 \mu \mathrm{M}$, HepG2 cells exhibited significant increase in $\mathrm{G} 2 / \mathrm{M}$ phase but obvious reduction in $S$ phase and even G0/G1 phase $(P<0.05)$. Figure 3 showed that $\mathrm{H}_{2} \mathrm{O}_{2}$ could cause a dose-dependent increase of cell apoptosis, especially early apoptosis. In the presence of 600 and $800 \mu \mathrm{M} \mathrm{H}_{2} \mathrm{O}_{2}$, a significant $(P<0.001)$ increase in cell early apoptosis of $20.9 \%$ and $58.0 \%$, respectively, was observed. These data suggested that $\mathrm{H}_{2} \mathrm{O}_{2}$ could induce cell cycle arrest in G2/M phase and promote a dose-dependent 

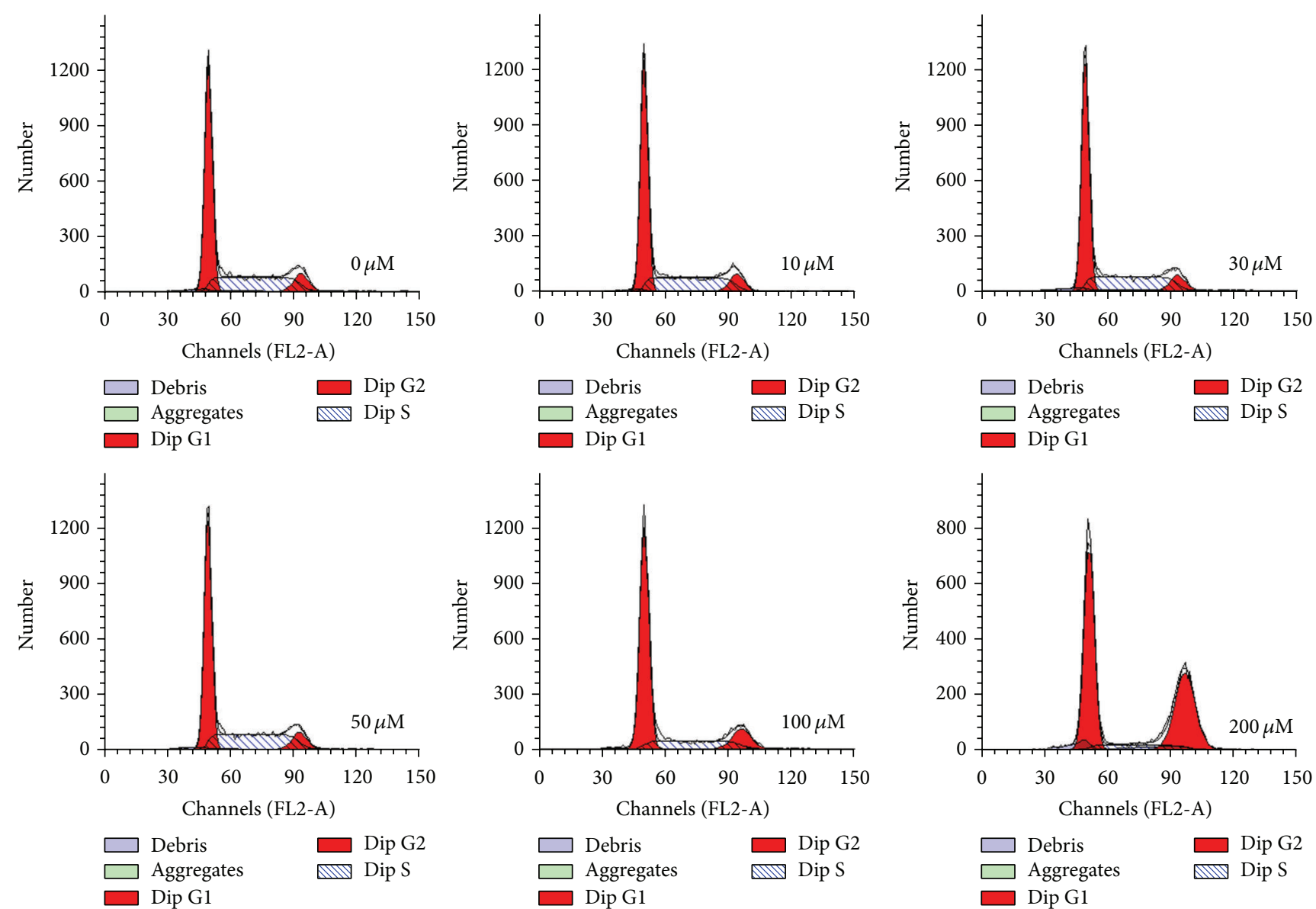

(a)

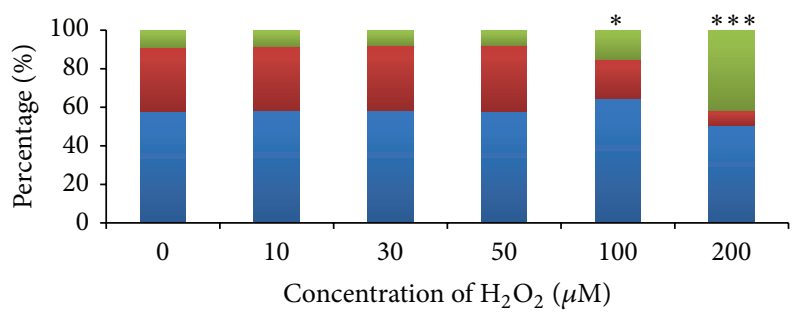

$\because \mathrm{G} 2 / \mathrm{M}$

- $\mathrm{S}$

- $\mathrm{G} 0 / \mathrm{G} 1$

(b)

Figure 2: $\mathrm{H}_{2} \mathrm{O}_{2}$ treatment induces cell cycle arrest in G2/M phase. (a) The cell cycle was analyzed by flow cytometry. After synchronization induced by serum starvation overnight, HepG2 cells were treated with $\mathrm{H}_{2} \mathrm{O}_{2}$ for $24 \mathrm{~h}$. (b) The histogram shows the cell cycle percentage detected by FCM. ${ }^{*} P<0.05 ;{ }^{* * *} P<0.001$.

cell apoptosis of HepG2 cells, which might directly cause the reduction of cell viability and proliferation.

\section{3. $\mathrm{H}_{2} \mathrm{O}_{2}$ Treatment Stimulates $\mathrm{ROS}$ in a Dose-Dependent} Manner. To confirm the ROS induction, FCM was used to detect the total ROS. As shown in Figure 4, $30 \mu \mathrm{M}$ of $\mathrm{H}_{2} \mathrm{O}_{2}$ did not increase ROS in HepG2 cells $(P>0.05)$. However, once the concentration of $\mathrm{H}_{2} \mathrm{O}_{2}$ was higher than $100 \mu \mathrm{M}$, ROS levels were significantly increased $(P<0.05)$. These data showed that $\mathrm{H}_{2} \mathrm{O}_{2}$ could also stimulate ROS in a dosedependent manner, which was consistent with the changes in cell biological functions.

3.4. Identification of miRNAs Modulated by Oxidative Stress. To verify whether miRNAs could be modulated by oxidative stress, we stimulated HepG2 cells with $\mathrm{H}_{2} \mathrm{O}_{2}$ to develop a cell model of oxidative stress. Taking into account the results listed above, we chose 30 and $600 \mu \mathrm{M}$ of $\mathrm{H}_{2} \mathrm{O}_{2}$ as low and 

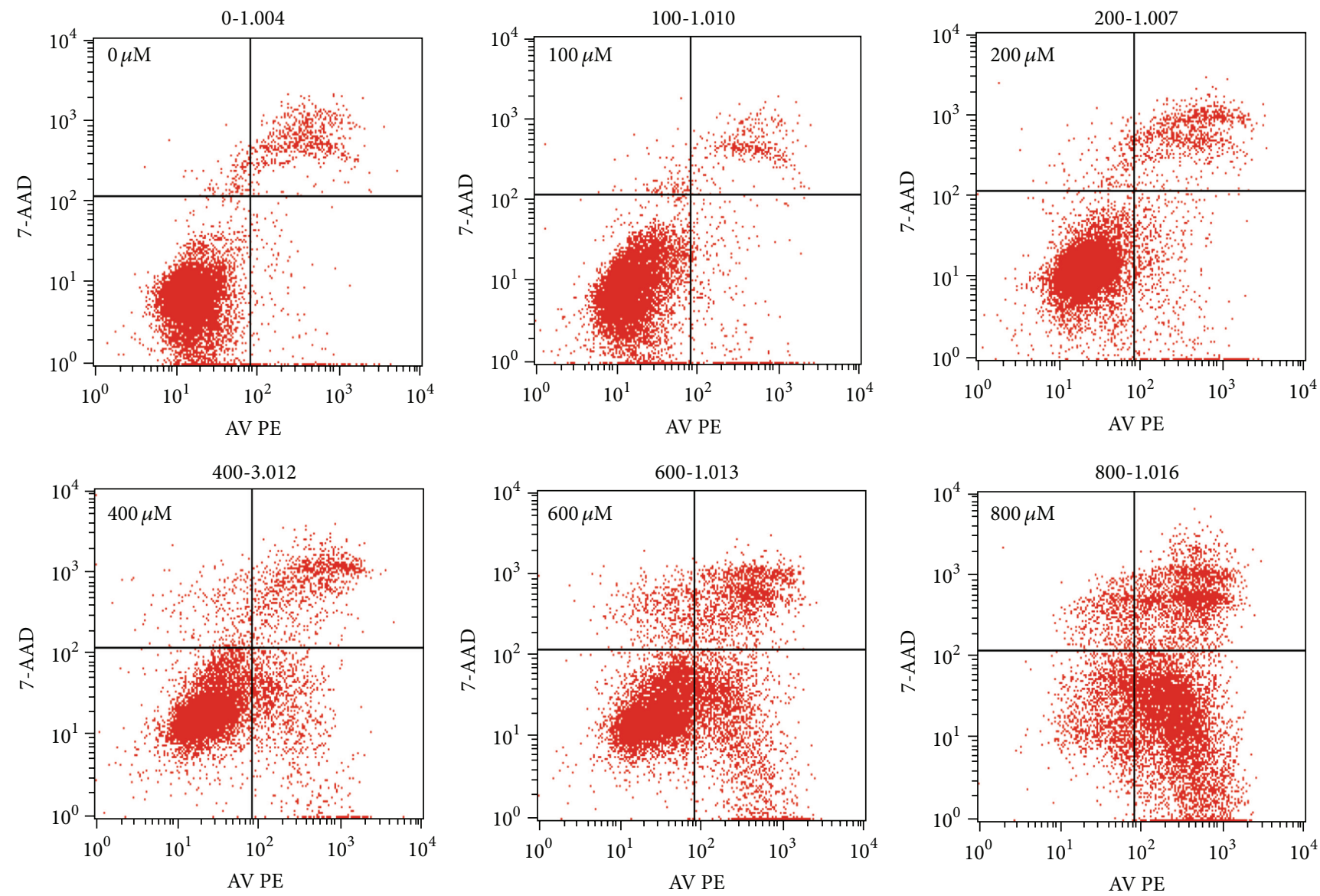

(a)

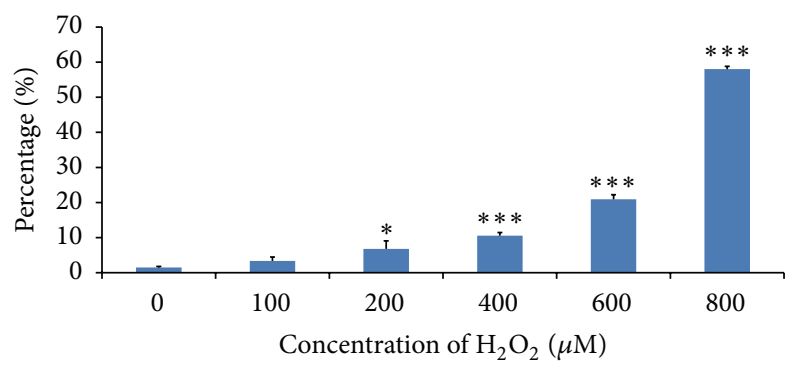

- Early apoptosis

(b)

FIGURE 3: $\mathrm{H}_{2} \mathrm{O}_{2}$ treatment induces cell apoptosis in a dose-dependent manner. (a) The cell apoptosis was analyzed by FCM assay. HepG2 cells were treated with $\mathrm{H}_{2} \mathrm{O}_{2}$ for $24 \mathrm{~h}$. (b) The histogram shows the early apoptotic cell percentage detected by FCM. ${ }^{*} P<0.05$; ${ }^{* * *} P<0.001$.

high concentrations for miRNAs profiling, respectively. After stimulating HepG2 cells for $24 \mathrm{~h}, \mathrm{H}_{2} \mathrm{O}_{2}$-induced changes in the miRNAs expression profiles were analyzed by the Affymetrix microRNA 4.0 Array, which contains 2578 probes and can interrogate all mature miRNAs sequences in miRBase Release 20. The results revealed that 131 miRNAs were deregulated in high concentration group under the condition of "Q $<0.05$ and fold change $>2$," compared with normal control. Among them, 125 miRNAs were upregulated and 6 were downregulated (Figure 5(a)). However, there were no statistically significant differences between low concentration group and normal control under the same condition. After adjusting the condition to "Q $<0.5$ and fold change $>1.2$," 16 deregulated miRNAs were determined in low concentration group, all of which were downregulated (Figure 5(b)). All of the deregulated miRNAs were listed in Supplementary Table 1 in Supplementary Material available online at http://dx.doi.org/10.1155/2016/7530853. Evidently, no deregulated miRNAs were overlapping between the two concentration groups. These data suggest that higher concentration of $\mathrm{H}_{2} \mathrm{O}_{2}$ mainly upregulated the expression of miRNAs, while lower concentration of $\mathrm{H}_{2} \mathrm{O}_{2}$ might have no effects and might 

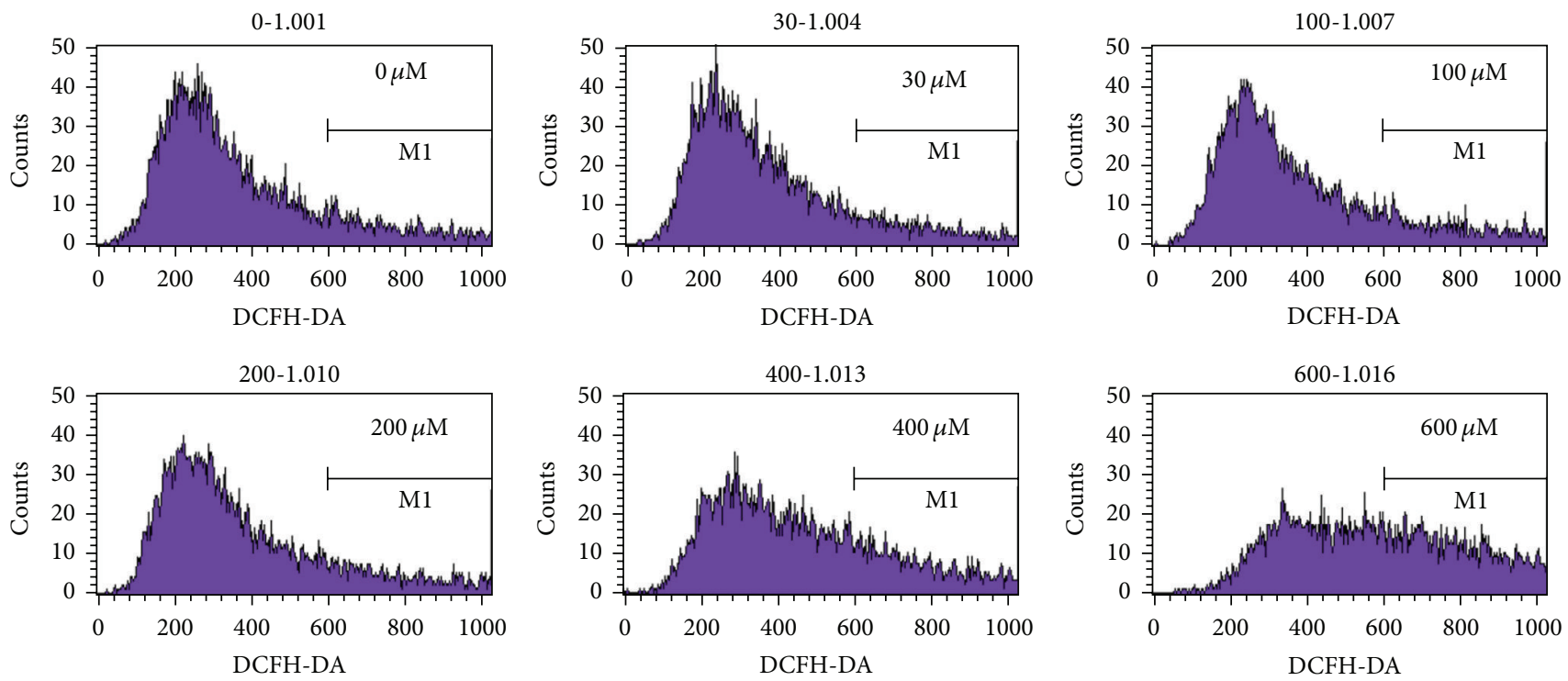

(a)

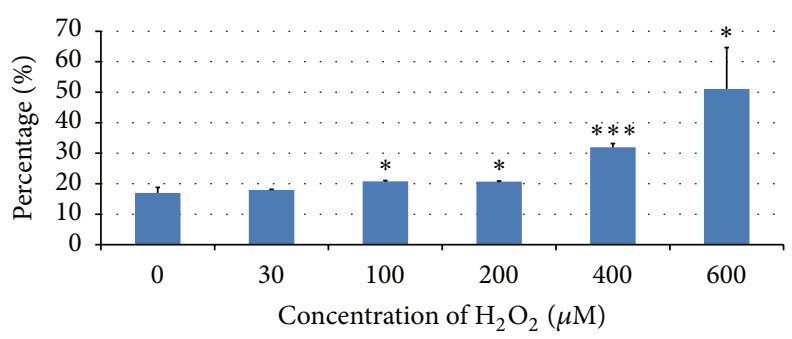

- ROS positive

(b)

FIGURE 4: $\mathrm{H}_{2} \mathrm{O}_{2}$ treatment stimulates ROS in a dose-dependent manner. (a) The total ROS was determined through FCM assay. HepG2 cells were treated with $\mathrm{H}_{2} \mathrm{O}_{2}$ for $24 \mathrm{~h}$. (b) The histogram shows the ROS positive cell percentage detected by FCM. ${ }^{*} P<0.05$; ${ }^{* * *} P<0.001$.

even play the opposite role in the miRNAs expression. In view of no statistical differences between the low concentration group and normal control, we did not pursue the subsequent bioinformatics analysis of that group.

3.5. Identification of $\mathrm{H}_{2} \mathrm{O}_{2}$-Sensitive miRNAs Putative Target Genes and GO/Pathway Enrichment Analysis. Our study has identified 131 miRNAs that were significantly deregulated in response to $600 \mu \mathrm{M} \mathrm{H}_{2} \mathrm{O}_{2}$, compared with normal control. As miRNAs play their biological roles through regulating target genes expression at the posttranscriptional level, we firstly predicted the target genes of $\mathrm{H}_{2} \mathrm{O}_{2}$-sensitive miRNAs by GCBI online tools, which are mainly based on the algorithms of miRanda and TargetScan. As a result, 13504 genes were predicted as putative target genes of high concentration $\mathrm{H}_{2} \mathrm{O}_{2}$ sensitive miRNAs.

To identify the biological functions of these genes, GO and pathway enrichment analysis were performed, respectively. As illustrated in Figure 6(a), the top ten deregulated GOs sensitive to high concentration of $\mathrm{H}_{2} \mathrm{O}_{2}$ were "transcription, DNA-dependent," positive regulation of transcription from RNA polymerase II promoter, signal transduction, negative regulation of transcription from RNA polymerase II promoter, axon guidance, nervous system development, "regulation of transcription, DNA-dependent," apoptotic process, and synaptic transmission. GO analysis obviously suggests that high concentration of $\mathrm{H}_{2} \mathrm{O}_{2}$ could affect expression of many miRNAs, through which many important functions such as transcription regulation, signal transduction, and apoptotic process are involved in apoptotic regulation of HepG2 cells. Combining with KEGG database, we analyzed the pathways in which the putative target genes were involved. As illustrated in Figure 6(b), the top ten deregulated pathways sensitive to high concentration of $\mathrm{H}_{2} \mathrm{O}_{2}$ were pathways in cancer, MAPK signaling pathway, axon guidance, endocytosis, focal adhesion, HTLV-I infection, regulation of actin cytoskeleton, proteoglycans in cancer, Wnt signaling pathway, and PI3K-Akt signaling pathway. Then, we performed Path-net analysis to draw an interaction network covering 61 significantly changed pathways (Figure 7). Among them, MAPK signaling pathway (degree $=44$ ), apoptosis $($ degree $=29)$, pathways in cancer $($ degree $=28)$, and cell cycle 


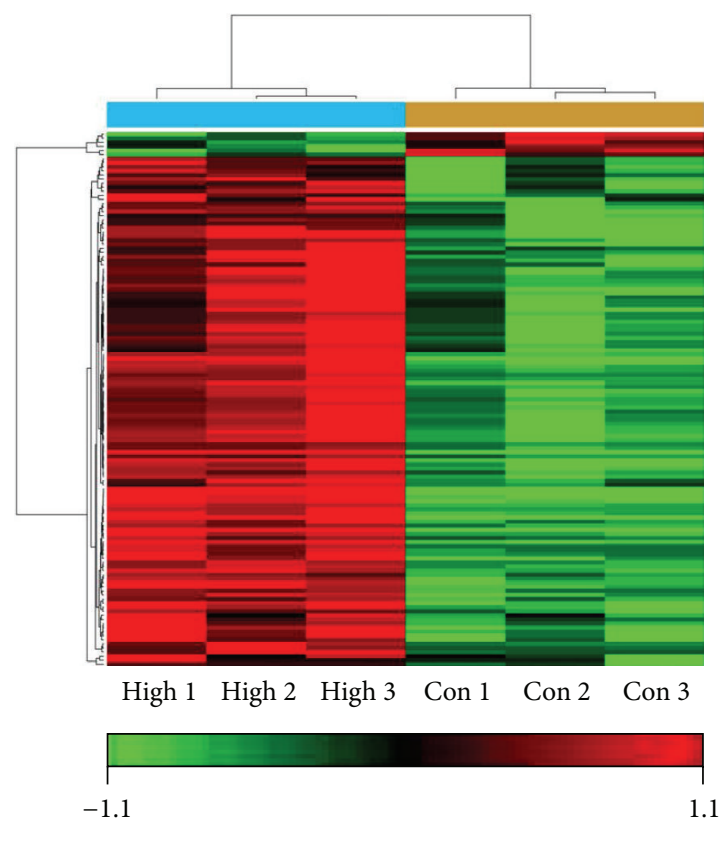

(a)

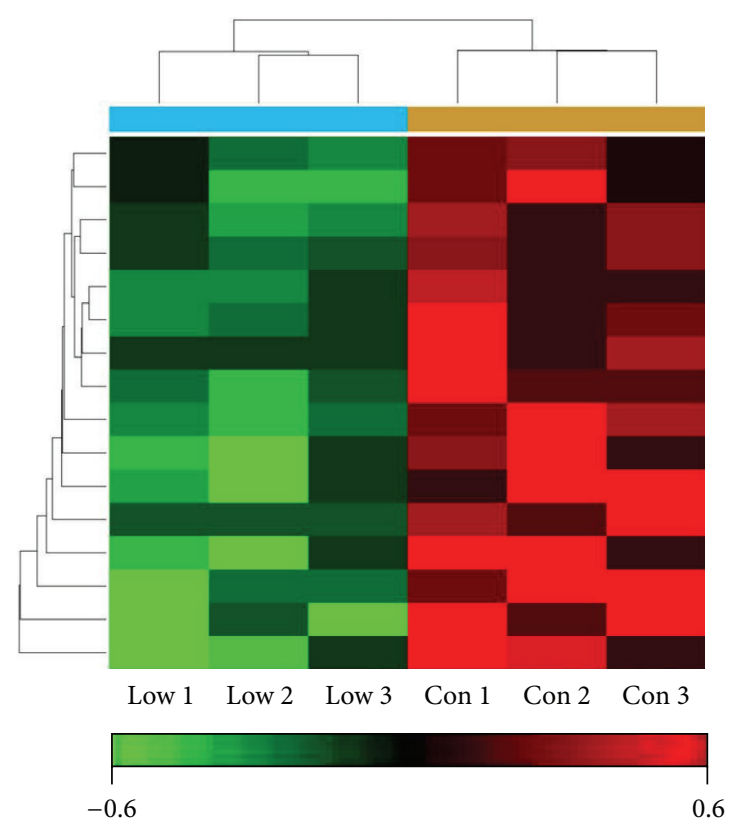

(b)

FIGURE 5: Changes in miRNAs expression profiles in $\mathrm{H}_{2} \mathrm{O}_{2}$ treated HepG2 cells. Total RNA was extracted from control group and HepG2 cells treated with 600 or $30 \mu \mathrm{M} \mathrm{H}_{2} \mathrm{O}_{2}$ for $24 \mathrm{~h}$. miRNAs microarray was performed as described in Materials and Methods. (a) High concentration versus control group, changes in miRNAs expression $>2$-fold, and $Q<0.05$ are illustrated by heat map. Green indicates a relatively low expression and red indicates a relatively high expression. (b) Low concentration versus control group, changes in miRNAs expression $>1.2-$ fold, and $Q<0.5$ are illustrated by heat map. High: high concentration of $\mathrm{H}_{2} \mathrm{O}_{2}$ group, $600 \mu \mathrm{M}$; Con: control group; Low: low concentration of $\mathrm{H}_{2} \mathrm{O}_{2}$ group, $30 \mu \mathrm{M}$.

(degree $=24)$ showed the highest degree, suggesting that these four pathways might play a core role in apoptosis induced by $\mathrm{H}_{2} \mathrm{O}_{2}$ treatment.

Based on the significantly regulated GOs and pathways, we selected intersected genes and further constructed miRNAs-gene-networks and miRNAs-GO-networks to screen the key regulatory functions of the identified miRNAs and their target genes, respectively. As shown in Figures 8 and 9 and Table 1, the top rated six miRNAs from the two analyses were the same, including hsa-miR-4763-3p, hsa-miR-149-3p, hsa-miR-762, hsa-miR-5001-5p, hsa-miR-5787, and hsa-miR6791-5p. All of these miRNAs were upregulated by $\mathrm{H}_{2} \mathrm{O}_{2}$ treatment in HepG2 cells during apoptosis. The top six target genes were CPLX2 (complexin 2), ZNF385A (zinc finger protein 385A), NFIX (nuclear factor I/X (CCAAT-binding transcription factor)), CNIH2 (cornichon family AMPA receptor auxiliary protein 2), SOX12 (SRY- (sex determining region Y-) box 12), and WDTC1 (WD and tetratricopeptide repeats 1). Our analysis also showed that the deregulated miRNAs mainly play vital roles in various biological processes, including transcription regulation, apoptotic process, gene expression, and signal transduction. Taken together, these results represented comprehensive information on the biological function of $\mathrm{H}_{2} \mathrm{O}_{2}$ treatment in HepG2 cells. Through deregulation of certain miRNAs and several important pathways, elevated concentrations of $\mathrm{H}_{2} \mathrm{O}_{2}$ could decrease cell viability, inhibit cell proliferation, induce cell cycle arrest, and finally promote cell apoptosis in HepG2 cells.

\section{Discussion}

$\mathrm{H}_{2} \mathrm{O}_{2}$, one of the most studied ROS, is a protonated form of $\mathrm{O}_{2}{ }^{-}$and can produce $\mathrm{OH}^{*}$ in the presence of transition metals like cupper or iron. $\mathrm{H}_{2} \mathrm{O}_{2}$ is also a hypochlorous acid precursor $[17,18]$. As a soluble lipid, this strong oxidizing agent has been found to diffuse throughout the cell membrane via some aquaporins and can cause damage of cellular membranes, proteins, and DNA $[19,20]$. Although $\mathrm{H}_{2} \mathrm{O}_{2}$ is widely used as oxidative stress stimuli, little is known about the biological functions of it on HepG2 cells. To investigate the role of $\mathrm{H}_{2} \mathrm{O}_{2}$ on HepG2 cells, we comprehensively examined the changes in cell biological functions, including cell viability, proliferation, cycle, and apoptosis. Specifically, $\mathrm{H}_{2} \mathrm{O}_{2}$ could significantly decrease cell viability and inhibit proliferation around $70.3 \mu \mathrm{M}$, which was calculated as the IC50 value. Once the concentration of $\mathrm{H}_{2} \mathrm{O}_{2}$ is higher than $100 \mu \mathrm{M}$, it can significantly induce cell cycle arrest in $\mathrm{G} 2 / \mathrm{M}$ phase $(P<$ 0.05). Meanwhile, if the concentration of $\mathrm{H}_{2} \mathrm{O}_{2}$ is higher than $200 \mu \mathrm{M}$, it can obviously promote cell early apoptosis $(P<0.05)$. In contrast, HepG2 cells exhibit no statistically significant changes under the treatment of low concentration of $\mathrm{H}_{2} \mathrm{O}_{2}$. In general, $\mathrm{H}_{2} \mathrm{O}_{2}$ could decrease cell viability, inhibit cell proliferation, induce cell cycle arrest, and finally promote cell apoptosis in a dose-dependent manner. These results suggested that $\mathrm{H}_{2} \mathrm{O}_{2}$ may be used as an anticancer agent if used at appropriate concentrations [21, 22]. Indeed, many chemotherapy drugs play their roles in killing tumor cells by producing ROS [10]. It could be confirmed from another 
TABLE 1: The top 10 miRNAs with high degrees of miRNAs-gene-networks and miRNAs-GO-networks.

\begin{tabular}{|c|c|c|c|c|c|c|}
\hline \multirow{2}{*}{ Rank } & \multicolumn{3}{|c|}{ miRNAs-gene-networks } & \multicolumn{3}{|c|}{ miRNAs-GO-networks } \\
\hline & miRNAs & Degree & Feature & miRNAs & Degree & Feature \\
\hline 1 & hsa-miR-4763-3p & 265 & Up & hsa-miR-4763-3p & 436 & Up \\
\hline 2 & hsa-miR-149-3p & 251 & Up & hsa-miR-149-3p & 408 & Up \\
\hline 3 & hsa-miR-762 & 211 & Up & hsa-miR-762 & 346 & Up \\
\hline 4 & hsa-miR-5001-5p & 207 & Up & hsa-miR-6791-5p & 337 & Up \\
\hline 5 & hsa-miR-5787 & 195 & Up & hsa-miR-5001-5p & 336 & Up \\
\hline 6 & hsa-miR-6791-5p & 188 & Up & hsa-miR-5787 & 333 & Up \\
\hline 7 & hsa-miR-4498 & 180 & Up & hsa-miR-2861 & 332 & Up \\
\hline 8 & hsa-miR-4651 & 164 & Up & hsa-miR-4505 & 322 & Up \\
\hline 9 & hsa-miR-4505 & 159 & Up & hsa-miR-4498 & 320 & Up \\
\hline 10 & hsa-miR-4632-5p & 150 & Up & hsa-miR-665 & 303 & Up \\
\hline
\end{tabular}

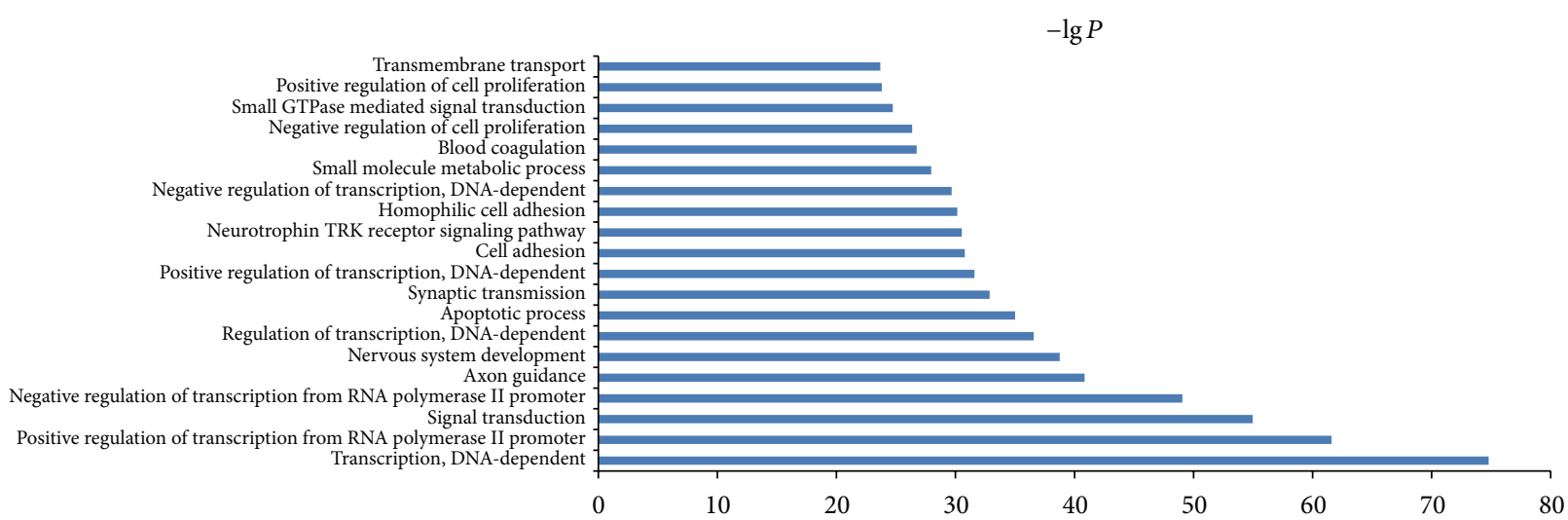

(a)

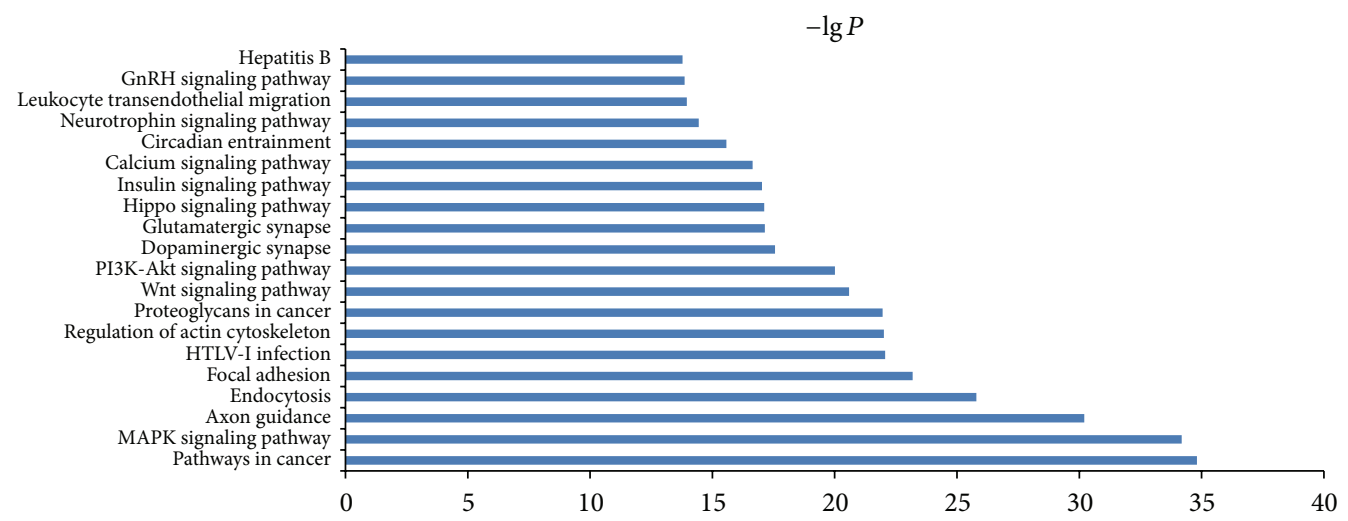

(b)

FIGURE 6: Significantly changed GO/pathways of predicted target genes of deregulated miRNAs after $\mathrm{H}_{2} \mathrm{O}_{2}$ treatment (600 $\mu$ M). (a) Significantly changed GOs of predicted target genes. The $y$-axis shows GO category and the $x$-axis shows $-\lg P$. The $\operatorname{larger}-\lg P$ indicated a smaller $P$ value. (b) Significantly changed pathways of predicted target genes. The $y$-axis shows significantly changed pathways. $-\lg P$ : negative logarithm of the $P$ value.

perspective that several clinical trials based on the concept that oxidants were toxic and antioxidants were favorable for cancer prevention were largely unsuccessful [23].

As mentioned above, DNA damage responses induced by $\mathrm{H}_{2} \mathrm{O}_{2}$ usually end up with the decrease of cell viability and promotion of apoptosis. In addition to its effects on apoptosis, $\mathrm{H}_{2} \mathrm{O}_{2}$ could also induce necrosis or autophagy depending on the stimulus intensity. Thus, $\mathrm{H}_{2} \mathrm{O}_{2}$ leads to cell death in different manners [24-27]. In this study, we found that $100 \mu \mathrm{M} \mathrm{H}_{2} \mathrm{O}_{2}$ could decrease the cell viability to nearly $10 \%$ and induce obvious cell proliferation inhibition and cycle arrest, but there are no statistically significant differences in apoptosis under the same condition. This discrepancy might be caused by the following reasons. Firstly, different 


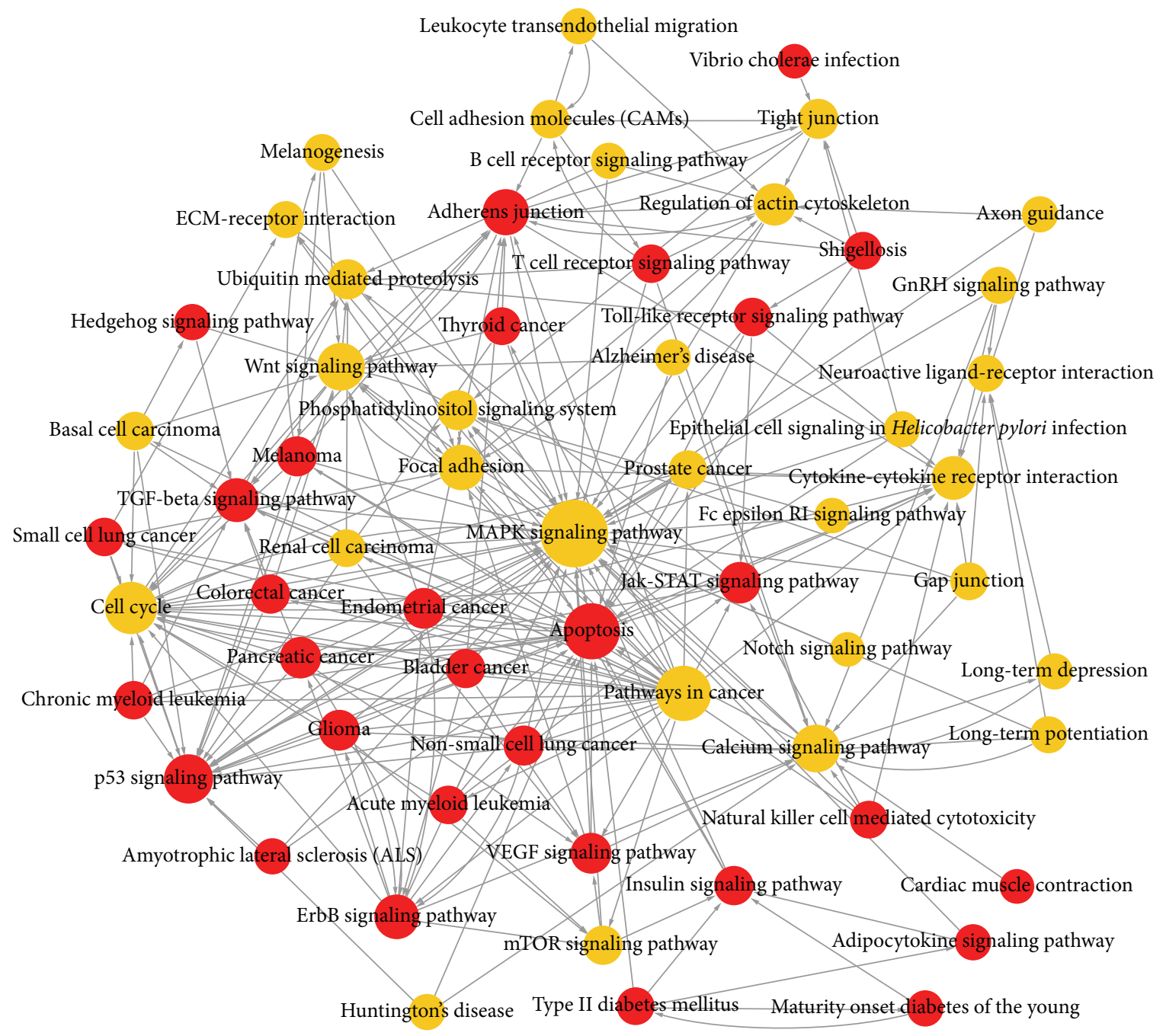

Figure 7: Pathway network (Path-net). Significantly changed pathways were connected in a Path-net to show the interaction network among these pathways. Each pathway in the network was measured by counting the upstream and downstream pathways. The red circle represents pathways involving upregulated miRNAs, while the yellow circle represents pathways involving both upregulated and downregulated miRNAs. The size of the circle represents the degree value and the lines show the interaction between pathways. A higher degree of pathway indicates that it plays a more important role in the signaling network.

methodologies may lead to the inconsistent results. Specifically, cell viability and proliferation were detected by CCK- 8 assay, while cell cycle and apoptosis were analyzed by FCM. Secondly, under the treatment of $100 \mu \mathrm{M} \mathrm{H}_{2} \mathrm{O}_{2}$, nearly $90 \%$ reduction of cell viability was caused by multiple mechanisms, including cell apoptosis, necrosis, and autophagy. Finally, although $\mathrm{H}_{2} \mathrm{O}_{2}$ could induce biological changes in a dose-dependent manner, the potentially different sensitivity or reactivity of various biological functions, such as cell viability, cell proliferation, cell cycle, and cell apoptosis, might lead to the discrepancy. In other words, these biological functions react or adapt differently to $100 \mu \mathrm{M} \mathrm{H}_{2} \mathrm{O}_{2}$ treatment.

Furthermore, to confirm the induction of ROS by $\mathrm{H}_{2} \mathrm{O}_{2}$ treatment, we used FCM to detect the total ROS. Our results showed that $100 \mu \mathrm{M}$ of $\mathrm{H}_{2} \mathrm{O}_{2}$ could significantly induce ROS $(P<0.05)$ and it also stimulates ROS in a dose-dependent manner. Although oxidative stress is closely related with liver cancer, further and detailed investigation is required to elucidate the molecular mechanisms of the interaction among oxidative stress, miRNAs, and liver cancer. By comparing the miRNAs expression profiles of control and high concentration group $(600 \mu \mathrm{M})$, we identified 131 differentially expressed miRNAs $(Q<0.05$, fold change $>2)$, of which 125 were upregulated and 6 were downregulated (Figure 5(a)). However, only 16 downregulated miRNAs could be determined in low concentration group after adjusting the condition to " $Q<$ 0.5 and fold change $>1.2$ " (Figure 5(b)). These data suggest that higher concentration of $\mathrm{H}_{2} \mathrm{O}_{2}$ mainly upregulated the expression of miRNAs, while lower concentration of $\mathrm{H}_{2} \mathrm{O}_{2}$ might play the opposite role on the miRNAs expression. In view of the fact that miRNAs generally inhibit translation of their target genes, we could easily deduce that higher concentration of $\mathrm{H}_{2} \mathrm{O}_{2}$ mainly downregulates the translation of target proteins, while lower concentration of $\mathrm{H}_{2} \mathrm{O}_{2}$ might 


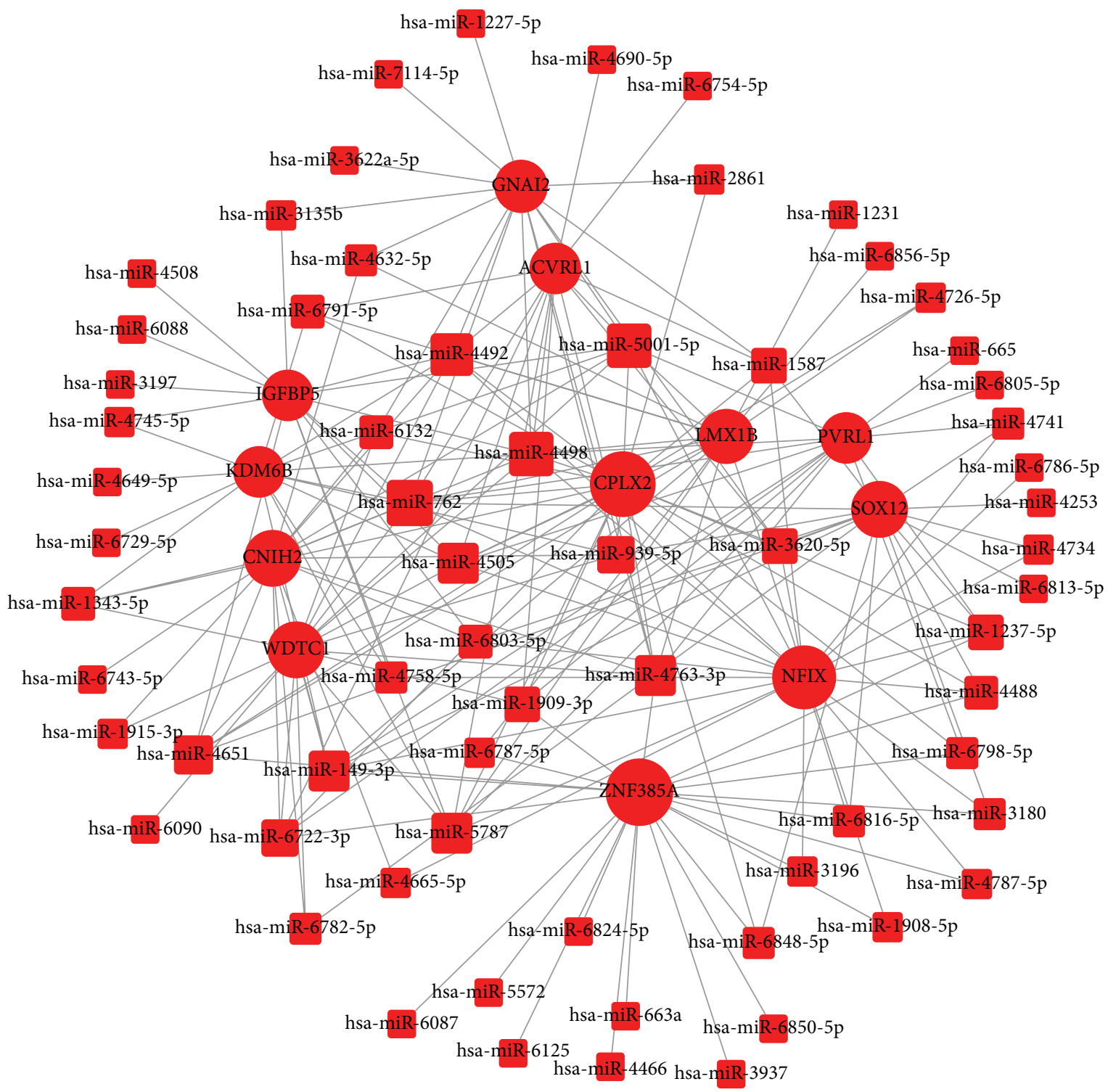

FIGURE 8: miRNAs-gene-network. According to the interactions between miRNAs and the intersected target genes, miRNAs-gene-network was constructed to illustrate the key regulatory functions of the identified miRNAs and their target genes. The red circles represent genes, while red square nodes represent upregulated miRNAs. The size of the circle or square node represents the degree value. A higher degree of gene/miRNAs indicates that it plays a more important role in the signaling network.

play the opposite role. Among the top ten fold changed miRNAs (Supplementary Table 1), half of them (hsa-miR-371b5p, hsa-miR-663a, hsa-miR-1225-5p, hsa-miR-1202, and hsamiR-572) were closely linked to the occurrence and development of tumors and might play vital roles as oncogenes or tumor suppressor genes [28-31]. These data confirmed that oxidative stress could interplay with cancer biology through modulating specific miRNAs expression. However, the rest of the top changed miRNAs were relatively novel miRNAs, which are rarely studied before and their functions are mostly unknown.

Then, 13504 genes were predicted as putative target genes of high concentration $\mathrm{H}_{2} \mathrm{O}_{2}$-sensitive miRNAs using target prediction methods. According to the result of $\mathrm{GO}$ analysis, the predicted target genes were mainly involved in transcription, signal transduction, regulation of transcription, apoptotic process, and synaptic transmission (Figure 6(a)). These biological processes are reported to be crucial in the regulation of apoptosis. As for biological pathways, pathways in cancer, MAPK signaling pathway, endocytosis, focal adhesion, proteoglycans in cancer, Wnt signaling pathway, and PI3K-Akt signaling pathway were the top enriched pathways of the predicted target genes (Figure 6(b)). It is well known that these pathways play important roles in regulation of cell apoptosis and survival outcome. The Path-net analysis covering 61 significantly changed pathways showed that MAPK signaling pathway, apoptosis, pathways in cancer, and cell cycle play a more important role in apoptosis induced by $\mathrm{H}_{2} \mathrm{O}_{2}$ 


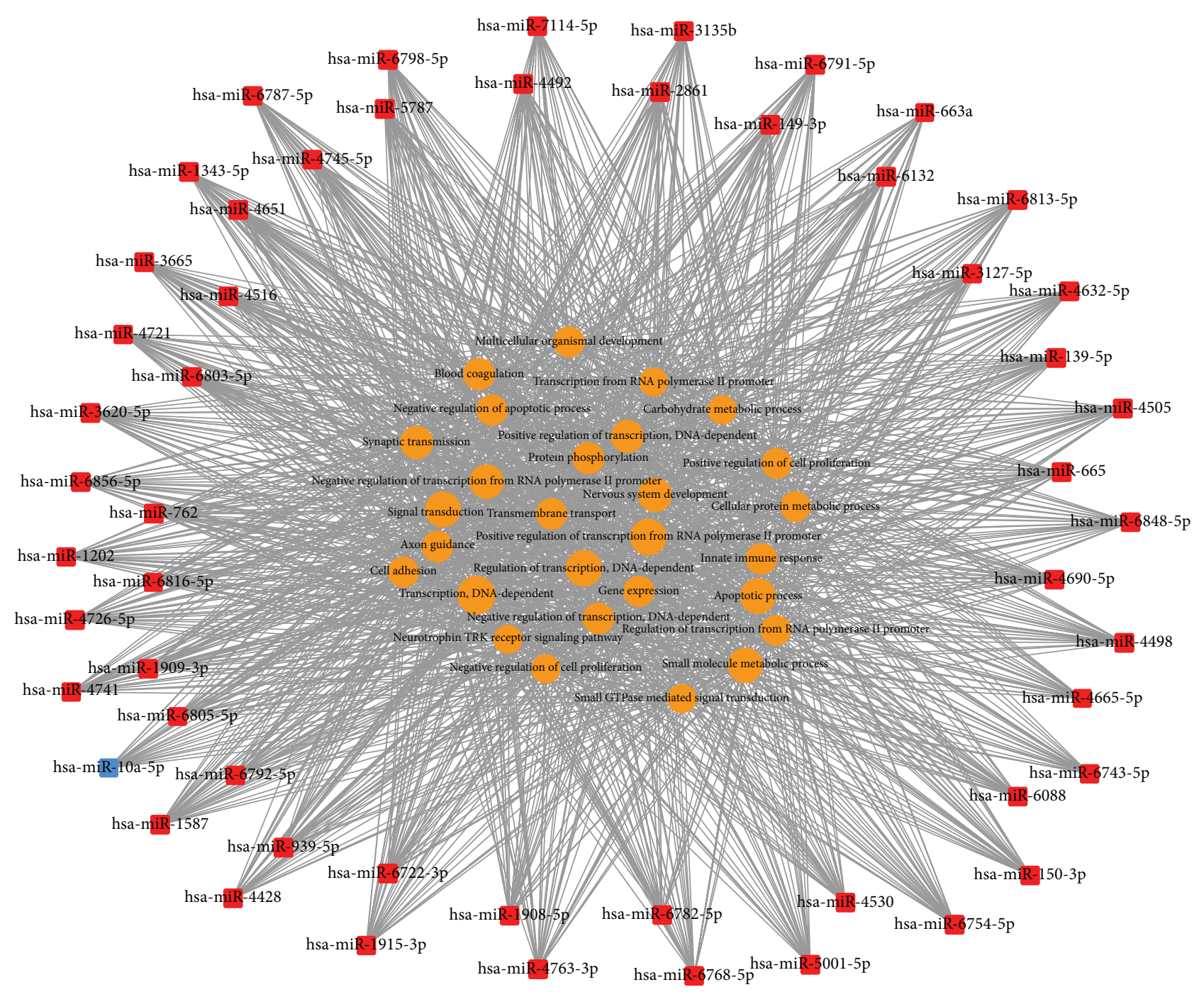

FIGURE 9: miRNAs-GO-network. The miRNAs-GO-network was generated according to the relationship of significant biological functions and miRNAs. The yellow circles represent GOs, red square nodes represent upregulated miRNAs, and blue square nodes represent downregulated miRNAs. The size of the circle or square node represents the degree value. A higher degree of GO/miRNAs indicates that it plays a more important role in the signaling network.

treatment (Figure 7). To screen for the important genes involved in apoptosis regulated by $\mathrm{H}_{2} \mathrm{O}_{2}$ in HepG 2 cells, we performed regulatory network analysis by overlapping the significantly regulated miRNAs, GOs, and pathways. The results showed that the top six miRNAs were hsa-miR-47633p, hsa-miR-149-3p, hsa-miR-762, hsa-miR-5001-5p, hsamiR-5787, and hsa-miR-6791-5p, while the top six target genes were CPLX2, ZNF385A, NFIX, CNIH2, SOX12, and WDTC1 (Figures 8 and 9). Taken together, these data suggest that $\mathrm{H}_{2} \mathrm{O}_{2}$ treatment may regulate biological functions of HepG2 cells through the changes in expression of specific miRNAs.

However, it is well acknowledged that predicting the miRNAs targets merely by the means of bioinformatics is not sufficient. miRNAs targets should be strictly verified by further functional experiments, such as gain or loss of miRNAs function, luciferase report assay, and western blot confirmation $[32,33]$. Therefore, our future investigations will be aimed at picking up some significantly deregulated miRNAs and carrying out experiments to confirm their targets and then unveil the mechanisms involved in the interplay among oxidative stress, miRNAs, and cancer.

\section{Conclusions}

Since $\mathrm{H}_{2} \mathrm{O}_{2}$ could decrease cell viability, inhibit proliferation, induce cycle arrest, and promote apoptosis in a dosedependent manner, this ROS is a very promising potential therapeutic tool to fight cancer. The proper and cautious use of $\mathrm{H}_{2} \mathrm{O}_{2}$ in combination with significantly deregulated miRNAs' mimics or antagomirs may have synergistic effects on increasing liver cancer cell death. 


\section{Competing Interests}

The authors declare that there is no conflict of interests regarding the publication of this paper.

\section{Acknowledgments}

This study was supported by the National High Technology Research and Development Program of China (863 Program, no. 2011AA02A111) and the National Natural Science Foundation of China (no. 81371906; no. 21375133). The authors wish to thank Dr. Wenjing Zhao (Genminix Informatics Co., Ltd., Shanghai, China) for providing help in bioinformatics analysis of miRNAs array data.

\section{References}

[1] B. D. Addissie and L. R. Roberts, "Classification and staging of hepatocellular carcinoma: an aid to clinical decision-making," Clinics in Liver Disease, vol. 19, no. 2, pp. 277-294, 2015.

[2] K. A. McGlynn, J. L. Petrick, and W. T. London, "Global epidemiology of hepatocellular carcinoma: an emphasis on demographic and regional variability," Clinics in Liver Disease, vol. 19, no. 2, pp. 223-238, 2015.

[3] Z. Ben Ari, E. Weitzman, and M. Safran, "Oncogenic viruses and hepatocellular carcinoma," Clinics in Liver Disease, vol. 19, no. 2, pp. 341-360, 2015.

[4] J. U. Marquardt, J. B. Andersen, and S. S. Thorgeirsson, "Functional and genetic deconstruction of the cellular origin in liver cancer," Nature Reviews Cancer, vol. 15, no. 11, pp. 653-667, 2015.

[5] H. Nakagawa and S. Maeda, "Inflammation- and stress-related signaling pathways in hepatocarcinogenesis," World Journal of Gastroenterology, vol. 18, no. 31, pp. 4071-4081, 2012.

[6] J. Arauz, E. Ramos-Tovar, and P. Muriel, "Redox state and methods to evaluate oxidative stress in liver damage: from bench to bedside," Annals of Hepatology, vol. 15, no. 2, pp. 160-173, 2016.

[7] B. Knoops, V. Argyropoulou, S. Becker, L. Ferté, and O. Kuznetsova, "Multiple roles of peroxiredoxins in inflammation," Molecules and Cells, vol. 39, no. 1, pp. 60-64, 2016.

[8] C. Nathan and A. Cunningham-Bussel, "Beyond oxidative stress: an immunologist's guide to reactive oxygen species," Nature Reviews Immunology, vol. 13, no. 5, pp. 349-361, 2013.

[9] G. S. Shadel and T. L. Horvath, "Mitochondrial ROS signaling in organismal homeostasis," Cell, vol. 163, no. 3, pp. 560-569, 2015.

[10] L. Tong, C.-C. Chuang, S. Wu, and L. Zuo, "Reactive oxygen species in redox cancer therapy," Cancer Letters, vol. 367, no. 1, pp. 18-25, 2015.

[11] Y. Wang and S. Hekimi, "Mitochondrial dysfunction and longevity in animals: untangling the knot," Science, vol. 350, no. 6265, pp. 1204-1207, 2015.

[12] V. Sosa, T. Moliné, R. Somoza, R. Paciucci, H. Kondoh, and M. E. LLeonart, "Oxidative stress and cancer: an overview," Ageing Research Reviews, vol. 12, no. 1, pp. 376-390, 2013.

[13] R. Cardin, M. Piciocchi, M. Bortolami et al., "Oxidative damage in the progression of chronic liver disease to hepatocellular carcinoma: an intricate pathway," World Journal of Gastroenterology, vol. 20, no. 12, pp. 3078-3086, 2014.

[14] S. H. Chew and S. Toyokuni, "Malignant mesothelioma as an oxidative stress-induced cancer: an update," Free Radical Biology and Medicine, vol. 86, Article ID 12414, pp. 166-178, 2015.
[15] S. Jonas and E. Izaurralde, "Towards a molecular understanding of microRNA-mediated gene silencing," Nature Reviews Genetics, vol. 16, no. 7, pp. 421-433, 2015.

[16] S. Lin and R. I. Gregory, "MicroRNA biogenesis pathways in cancer," Nature Reviews Cancer, vol. 15, no. 6, pp. 321-333, 2015.

[17] G. Manda, M. T. Nechifor, and T.-M. Neagu, "Reactive oxygen species, cancer and anti-cancer therapies," Current Chemical Biology, vol. 3, no. 1, pp. 22-46, 2009.

[18] V. J. Thannickal and B. L. Fanburg, "Reactive oxygen species in cell signaling," American Journal of Physiology-Lung Cellular and Molecular Physiology, vol. 279, no. 6, pp. L1005-L1028, 2000.

[19] G. P. Bienert, A. L. B. Møller, K. A. Kristiansen et al., "Specific aquaporins facilitate the diffusion of hydrogen peroxide across membranes," The Journal of Biological Chemistry, vol. 282, no. 2, pp. 1183-1192, 2007.

[20] B. Halliwell and J. Gutteridge, Free Radicals in Biology and Medicine, Oxford University Press, Oxford, UK, 2015.

[21] G. Vilema-Enríquez, A. Arroyo, M. Grijalva, R. I. AmadorZafra, and J. Camacho, "Molecular and cellular effects of hydrogen peroxide on human lung cancer cells: potential therapeutic implications," Oxidative Medicine and Cellular Longevity, vol. 2016, Article ID 1908164, 12 pages, 2016.

[22] M. López-Lázaro, "Dual role of hydrogen peroxide in cancer: possible relevance to cancer chemoprevention and therapy," Cancer Letters, vol. 252, no. 1, pp. 1-8, 2007.

[23] M. Goodman, R. M. Bostick, O. Kucuk, and D. P. Jones, “Clinical trials of antioxidants as cancer prevention agents: past, present, and future," Free Radical Biology and Medicine, vol. 51, no. 5, pp. 1068-1084, 2011.

[24] J.-P. Chen, D.-G. Xu, X.-Y. Yu et al., "Discrepancy between the effects of morronside on apoptosis in human embryonic lung fibroblast cells and lung cancer A549 cells," Oncology Letters, vol. 7, no. 4, pp. 927-932, 2014.

[25] H. Su, D.-D. Liu, M. Zhao et al., "Dual-enzyme characteristics of polyvinylpyrrolidone-capped iridium nanoparticles and their cellular protective effect against $\mathrm{H}_{2} \mathrm{O}_{2}$-induced oxidative damage," ACS Applied Materials and Interfaces, vol. 7, no. 15, pp. 8233-8242, 2015.

[26] S.-Y. Chiou, Y.-S. Lee, M.-J. Jeng, P.-C. Tsao, and W.-J. Soong, "Moderate hypothermia attenuates oxidative stress injuries in alveolar epithelial A549 cells," Experimental Lung Research, vol. 39, no. 6, pp. 217-228, 2013.

[27] J. Zhang, W. Zhou, J. Lin et al., "Autophagic lysosomal reformation depends on mTOR reactivation in $\mathrm{H}_{2} \mathrm{O}_{2}$-induced autophagy," International Journal of Biochemistry and Cell Biology, vol. 70, pp. 76-81, 2016.

[28] S. Mutlu, H. Mutlu, S. Kirkbes et al., "The expression of miR-181a-5p and miR-371b-5p in chondrosarcoma," European Review for Medical and Pharmacological Sciences, vol. 19, no. 13, pp. 2384-2388, 2015.

[29] M. E. C. Waaijer, M. Wieser, R. Grillari-Voglauer, D. Van Heemst, J. Grillari, and A. B. Maier, "MicroRNA-663 induction upon oxidative stress in cultured human fibroblasts depends on the chronological age of the donor," Biogerontology, vol. 15, no. 3, pp. 269-278, 2014.

[30] R. Hamam, A. M. Ali, K. A. Alsaleh et al., "microRNA expression profiling on individual breast cancer patients identifies novel panel of circulating microRNA for early detection," Scientific Reports, vol. 6, Article ID 25997, 2016.

[31] A.-H. Wu, Y.-L. Huang, L.-Z. Zhang, G. Tian, Q.-Z. Liao, and S.-L. Chen, "MiR-572 prompted cell proliferation of human 
ovarian cancer cells by suppressing PPP2R2C expression," Biomedicine and Pharmacotherapy, vol. 77, pp. 92-97, 2016.

[32] B. C. Bernardo, F. J. Charchar, R. C. Y. Lin, and J. R. McMullen, "A microRNA guide for clinicians and basic scientists: background and experimental techniques," Heart Lung and Circulation, vol. 21, no. 3, pp. 131-142, 2012.

[33] D. W. Thomson, C. P. Bracken, and G. J. Goodall, "Experimental strategies for microRNA target identification," Nucleic Acids Research, vol. 39, no. 16, pp. 6845-6853, 2011. 


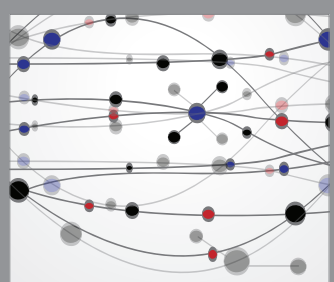

The Scientific World Journal
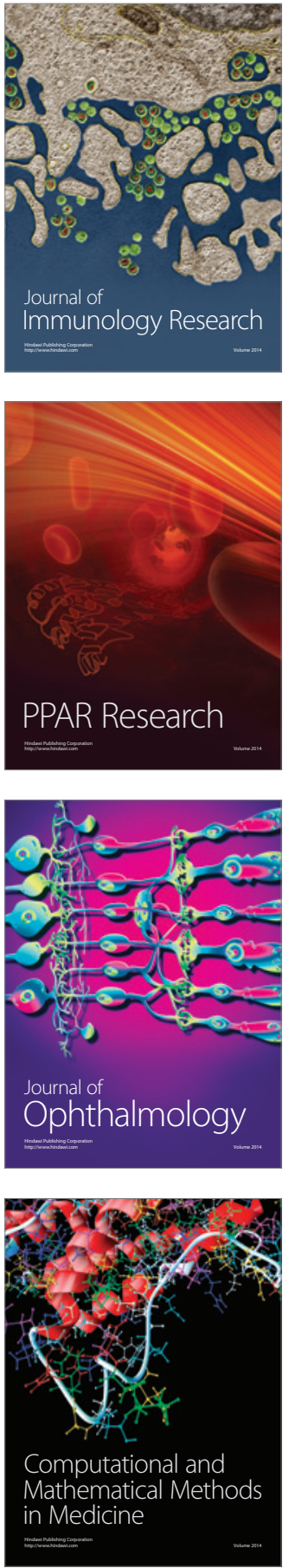

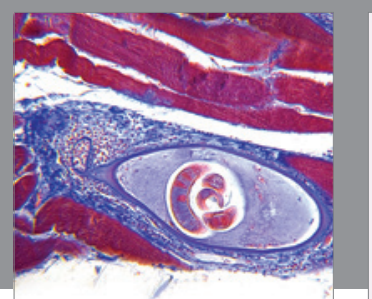

Gastroenterology Research and Practice

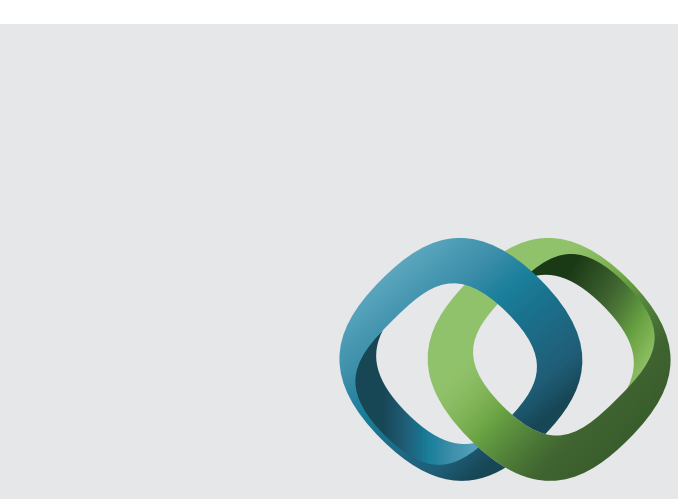

\section{Hindawi}

Submit your manuscripts at

http://www.hindawi.com
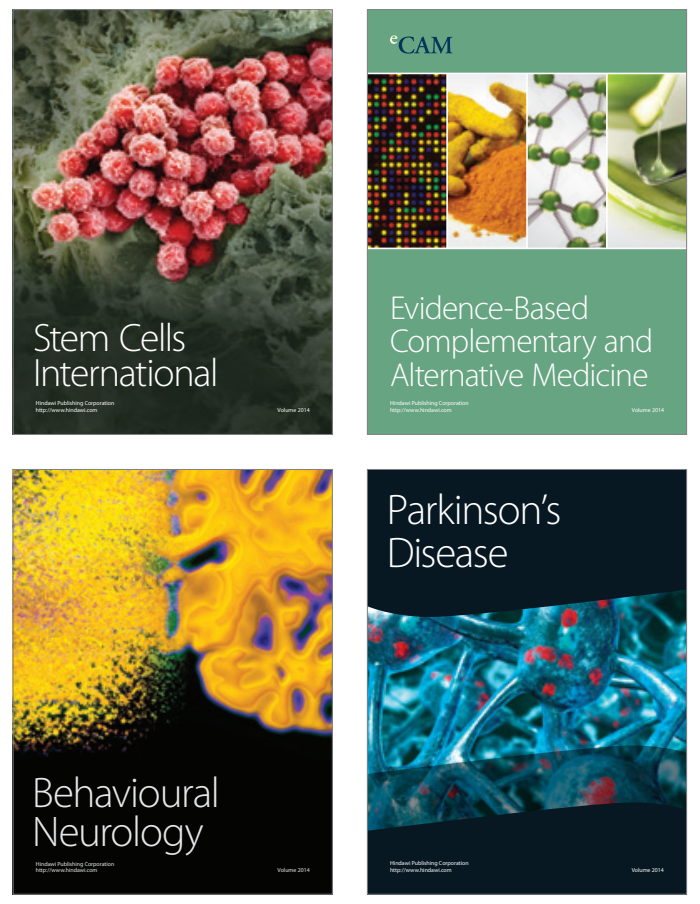
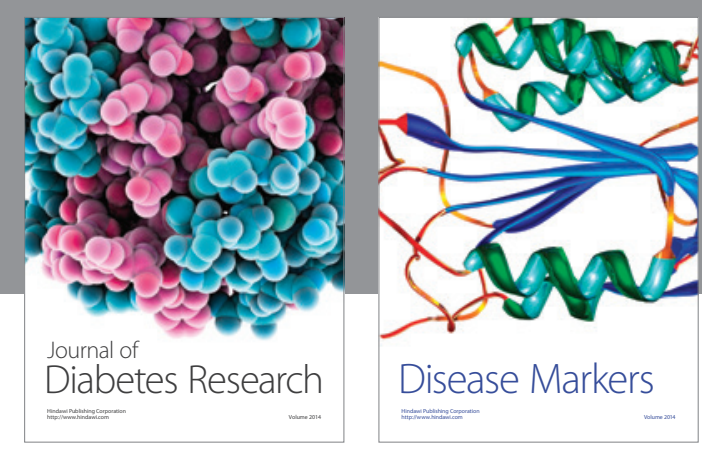

Disease Markers
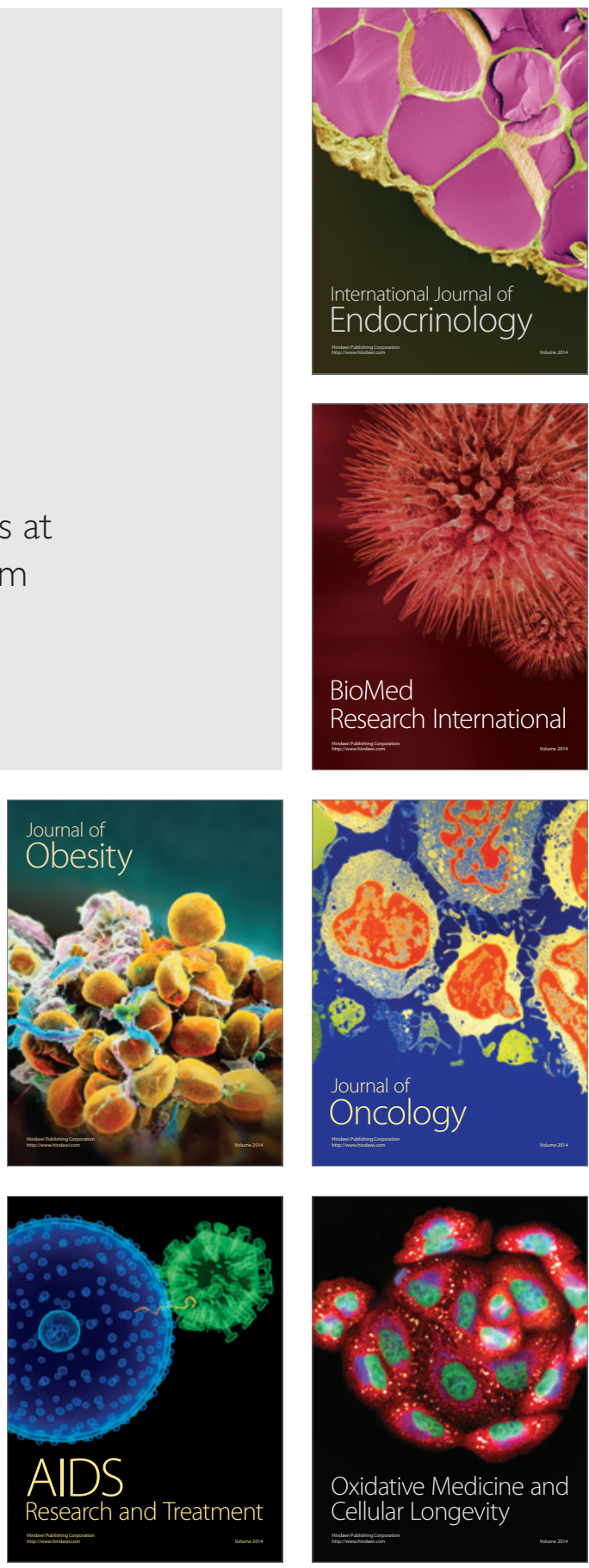